\title{
Defluoridation of water using biosorbents
}

\author{
Puthenveedu Sadasivan Pillai Harikumar, Chonattu Jaseela, Tharayil Megha \\ Water Quality Division, Centre for Water Resources Development and Management, Kozhikode, India; \\ *Corresponding Author: drpshari@yahoo.co.in
}

Received 29 October 2011; revised 30 November 2011; accepted 16 December 2011

\begin{abstract}
Contamination of drinking water due to fluoride is a severe health hazard problem. Excess of fluoride (>1.5 $\mathrm{mg} / \mathrm{l}$ ) in drinking water is harmful to human health. Various treatment technologies for removing fluoride from groundwater have been investigated. The present study showed that Vetiveria zizanioides, a herbal plant of Kerala-commonly known as Vetiver is an effective adsorbent for the removal of fluoride from aqueous solution. Phosphoric acid activated Vetiver root showed good adsorption capacity than the fresh powdered Vetiver root. Batch sorptive defluoridation was conducted under variable experimental conditions such as $\mathrm{pH}$, agitation time, dose of adsorbent and particle size. Maximum defluoridation was achieved at $\mathrm{pH} \mathrm{6}$; there is a greater possibility of columbic interaction between fluoride ion and adsorbent surface at this $\mathrm{pH}$. The percentage of fluoride removal increases with adsorbent dose and time at a given initial solute concentration. The surface and sorption characteristics were analyzed using SEM techniques. Freundlich as well as Langmuir isotherm were plotted and kinetic constants were determined.
\end{abstract}

Keywords: Defluoridation; Fluorosis; Batch

Adsorption; Vetiver; Phytoremediation

\section{INTRODUCTION}

Water is most abundant and is an essential component of our life supporting system. But today most of the countries are facing drinking water problems. In India, drinking water is contaminated at many places by various pollutants such as fluorides, nitrates, iron etc.

Fluoride is often considered as a "two edged sword" because deficiency of fluoride intake leads to dental caries while excess consumption leads to dental and skeletal fluorosis. Symptoms affecting the soft tissues such as muscles and ligaments are also reported [1]. Fluorosis is an important clinical and public health problem in several parts of the world. Global prevalence of fluorosis is reported to be about $32 \%$ [2].

Due to high toxicity of fluoride to mankind, there is an urgent need to treat fluoride-contaminated drinking water to make it safe for human consumption. According to World Health Organization (WHO), the maximum acceptable fluoride concentration in drinking water is 1.5 $\mathrm{mg} / \mathrm{L}$. From the literature surveys, the groundwater of the two districts in Kerala, India (Palakkad and Alleppy) shows high fluoride content [3].

The use of plant materials is a traditional technology for purifying potable water that is still in widespread use in rural areas of Latin America. The use of natural products has recently been rediscovered by water-supply technologists and is being further developed with more scientific rigour $[4,5]$.

The conventional method of fluoride removal includes: ion-exchange, reverse osmosis and adsorption $[4,6,7]$. The ion-exchange, reverse osmosis are relatively expensive. Therefore, still adsorption is the viable method for the removal of fluoride. Adsorption is the process considered to be efficient to defluoridate the water. Adsorption involves the passage of contaminated water through an adsorbent bed, where fluoride removed by physical, ion-exchange or surface chemical reaction with adsorbent. Because of its ease of operation and cost-effectiveness, adsorption is still widely accepted pollution removal technique. Plant materials are reported to accumulate fluoride and hence application as defluoridating agents has been suggested. The use of medicinal plant materials for the fluoride removal was investigated.

Several publications are available on the effective removal of fluoride using low cost materials. The tested materials include activated alumina, amorphous alumina, activated carbon, calcite, zeolite clay, charcoal, bleaching earth, red mud etc [1,8-12]. The materials like kaolinite, bentonite, charfines, lignite and nirmali seeds were also investigated for the removal of fluoride [13].

Kerala is one of the states in southern India, which has a rich biodiversity of medicinal plants. In the present 
study, the efficiency of removal of fluoride by using various locally available medicinal plants from Kerala was investigated. The study assesses the suitability of inexpensive adsorbents to effectively remediate fluoride contaminated water. The study investigated defluoridation capacities of the following plant materials-Ramacham (Vetiveria zizanioides), Tamarind seed (Tamarindus indica), Clove (Eugenia carryophyllata), Neem (Azadirachta indica), Acacia (Acacia catechu willd), Nutmeg (Myristica fragarns), and coffee husk (Coffea arabica) which are grown indigenously Kerala [2].

Effect of important controlling factors, viz $\mathrm{pH}$, dose of adsorbent, contact time, particle size and initial fluoride ion concentration on the fluoride removal efficiency was studied. The kinetics of removal was studied and the mechanism of removal suggested is controlled by adsorption and inter particle bridging.

\section{MATERIALS AND METHODS}

All the reagents used for the present study were of GR grade from E. Merck Ltd. India. A standard solution of $1000 \mathrm{ppm}$ fluoride was prepared by dissolving $2.21 \mathrm{~g}$ of anhydrous sodium fluoride in $1000 \mathrm{ml}$ of double distilled water. The fluoride solution of required concentration was prepared by diluting this standard solution. SPADNS spectrophotometric method was used to determine the fluoride concentration [14]. The instrument was calibrated and a curve was prepared using standard solutions.

The batch adsorption study was carried out in three stages-in the first stage; locally medicinal plants were selected as the study materials. Initial studies indicated that plants like Vetiver root, Tamarind seed and Clove were comparatively more efficient in the removal of fluoride. Activated form of Vetiver root has high degree of micro porosity and high surface area. The surface modification of activated Vetiver root as shown in Scanning Electron Microscope image. So in the third stage detailed studies on activated Vetiver root was carried out.

All the adsorbents used in this study were collected locally, washed well with tap water and then with distilled water, dried in an air oven at $110^{\circ} \mathrm{C}$ for 5 hour, micronized in a flour mill and sieved to get particles of sizes $0.1,0.20 .3,0.5 \mathrm{~mm}$. A synthetic solution of fluoride was prepared from analytical reagent sodium fluoride and stored in polythene bottles. The $\mathrm{pH}$ of the solution was adjusted to the required level, using $\mathrm{HCl}(0.1$ $\mathrm{mol} / \mathrm{l})$ and $\mathrm{NaOH}(0.1 \mathrm{~mol} / \mathrm{l})$ solutions [15].

Activation of Vetiver root was carried out by giving heat treatment (at $600^{\circ} \mathrm{C}-800^{\circ} \mathrm{C}$ ) and with the use of phosphoric acid in the ratio 1:4. The activated product is washed with water and dried. Activity was controlled by altering the proportion of raw material to activating agent, between the limits of 1:05 to 1:4.

\subsection{Batch Studies}

The batch experiments were carried out in $250 \mathrm{~mL}$ stoppered bottles by agitating a pre-weighed amount of the adsorbent with $50 \mathrm{~mL}$ of the fluoride solutions [15]. The adsorbent was separated with filter paper. The concentration of fluoride remaining in the filtrate was analyzed spectrophotometrically, using SPADNS reagent at $570 \mathrm{~nm}[14]$.

\subsection{Adsorption Isotherms}

Freundlich and Langmuir equations were used to find the patterns of adsorption by adsorbent activated Vetiver root for fluoride removal. The sorption isotherm studies are conducted by varying the initial concentration of fluoride from 1 to $5 \mathrm{mg} / \mathrm{L}$ and maintaining the adsorbent dosage of $0.5 \mathrm{~g}$.

\subsubsection{Freundlich Adsorption Isotherm}

The non-linear form of Freundlich equation is:

$$
\mathrm{X} / \mathrm{m}=\mathrm{KCe}^{1 / \mathrm{n}}
$$

where,

$\mathrm{X} / \mathrm{m}=$ Amount adsorbed per unit weight of adsorbent $(\mathrm{mg} / \mathrm{g})$ or adsorption capacity and is calculated as follows.

$\mathrm{X} / \mathrm{m}=(\mathrm{Ci}-\mathrm{Ce}) \times \mathrm{V} \times$ eq.wt. $/ 1000 \times \mathrm{m}$.

$\mathrm{Ci}=$ Initial concentration of solution in $\mathrm{mg} / \mathrm{L}$.

$\mathrm{Ce}=$ Equilibrium concentration of the solution in $\mathrm{mg} / \mathrm{L}$.

$\mathrm{V}=$ volume of the solution in $\mathrm{mL}$.

$\mathrm{K}=$ Constant of the system depending on temperature and is known as Freundlich adsorption coefficient. It represents the adsorption capacity.

$\mathrm{n}=$ Freundlich constant, which should be between 1 and 10 for favorable adsorption. Values of " $n$ " greater than unity suggest that adsorption is relatively more efficient at low concentration.

This equation is conveniently used in the linear form by taking the log on both sides as,

$$
\log (\mathrm{X} / \mathrm{m})=\log \mathrm{K}+(\mathrm{l} / \mathrm{n}) \log \mathrm{Ce}
$$

A plot of $\log (\mathrm{X} / \mathrm{m})$ against $\log \mathrm{p}$ or $\log \mathrm{Ce}$, yield a straight line. The constants $\mathrm{K}$ and $\mathrm{n}$ are determined from the intercept and slope respectively.

\subsubsection{Langmuir Adsorption Isotherm}

Langmuir equation is based on the assumption of a monolayer of adsorbate molecules. It is of the form,

$$
(\mathrm{X} / \mathrm{m})=\left(\mathrm{aV}_{\mathrm{m}} \mathrm{Ce}\right) /(1+\mathrm{aCe})
$$

where,

$\mathrm{a}=$ adsorption bond energy;

$\mathrm{V}_{\mathrm{m}}=$ maximum adsorption density (corresponding to 
monolayer formation on the adsorbent).

Linear form of the equation is,

$$
\mathrm{Ce} /(\mathrm{X} / \mathrm{m})=1 /\left(\mathrm{aV}_{\mathrm{m}}\right)+\left(1 / \mathrm{V}_{\mathrm{m}}\right) \mathrm{Ce}
$$

A plot of $\mathrm{Ce} /(\mathrm{X} / \mathrm{m})$ against $\mathrm{Ce}$, yield a straight line. The Langmuir constants a and $\mathrm{V}_{\mathrm{m}}$ were calculated from intercept and slope respectively.

\section{RESULTS AND DISCUSSION}

\subsection{Stage 1}

The first stage of the study provided the order of removal efficiency of different adsorbents from a solution contaminated with $2 \mathrm{mg} / \mathrm{L}$ fluoride. The order of removal of fluoride is: Vetiver root (Vetiveria zizanioides, 80\%), Tamarind seed (Tamarindus indica, 75\%), Clove (Eugenia carryophyllata, 70\%), Neem (Azadirachta indica 52\%), Acacia (Acacia catechu willd, 47\%), Nutmeg (Myristica fragarns, 45\%), and Cofee husk (Coffea arabica, 38\%) as shown in Figure 1. Effect of important controlling factors, viz, $\mathrm{pH}$, dose of adsorbent, contact time and initial fluoride ion concentration on the fluoride removal efficiency was studied. The kinetics of removal was studied and the mechanism of removal is due to adsorption and inter particle bridging.

\subsection{Stage 2}

The results of Batch sorptive defluoridation of Tamarind seed, Vetiver root and Clove was conducted under variable experimental conditions are discussed in the following section.

\subsubsection{Effect of Agitation Time}

The effect of agitation time was found to be increased up to a certain period of time after which the rate of sorption was found to be constant. In Figure 2 it was found that the percentage removal of fluoride for tama-

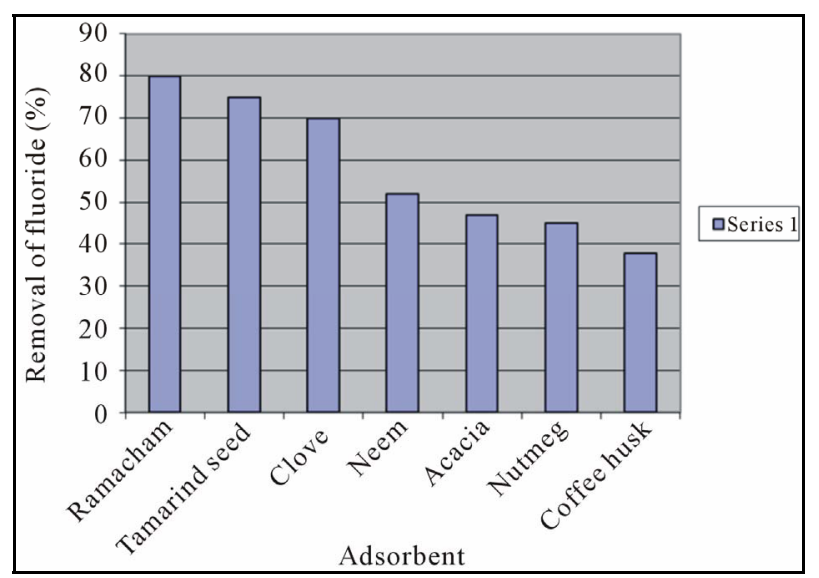

Figure 1. Comparison of fluoride removal efficiencies of different plant materials. rind seed, Vetiver root and clove was 51, 54, and 51 respectively.

\subsubsection{Effect of Sorbent Dosage}

As the weight of adsorbent dose increased the sorption percentage also increased. The response of adsorbent dose on the removal of fluoride is presented in Figure 3. This might be due to the fact that at higher doses of adsorbent, more sorbent surface and pore volume would be available for the adsorption interaction and this result in higher removal. It was also observed that, initially, the removal of fluoride increases with the dose but beyond certain dose range, there is no significant increase in removal. This perhaps is due to non-adsorbability of fluoride ion as result of sorbent-sorbate interaction. Results shows that the biosorbents, viz, Vetiver root removes $80 \%$ of fluoride at a dose of $1 \mathrm{~g}$ in $50 \mathrm{ml}$ of fluoridated water and tamarind seed and clove removes $75 \%$ and $70 \%$ at the same dose.

\subsubsection{Effect of Particle Size}

The effect of particle size on fluoride sorption is given in Figure 4. Increase in particle size reduces the sorption rate. Increase in particle size from 100 to 500 micron reduces the sorption level from 75 to 45 per cent. The breaking of larger particles tends to open tiny cracks and

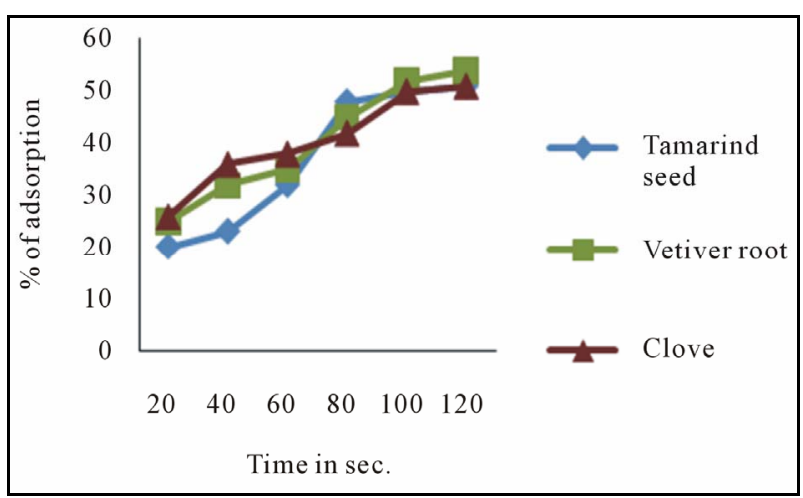

Figure 2. Effect of agitation time on defluoridation.

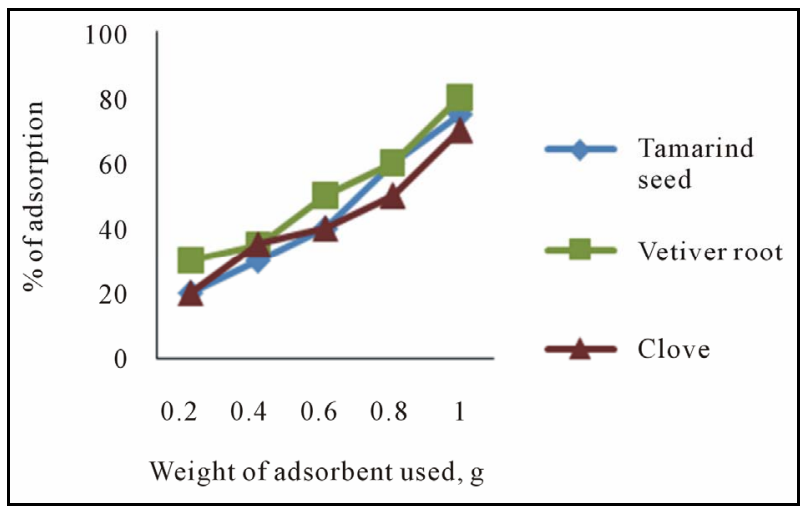

Figure 3. Effect of sorbent dosage on defluoridation. 


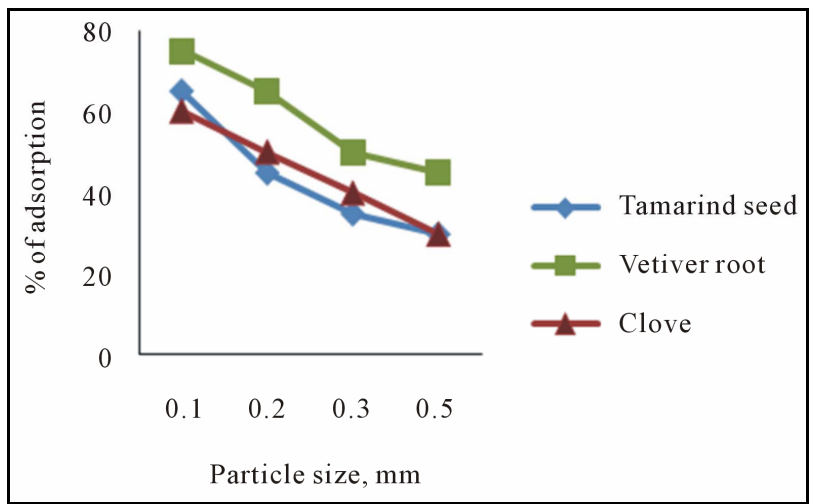

Figure 4. Effect of particle size on sorption of fluoride.

channels on the particle surface of the sorbent. The smaller particle provides more sorption sites and surface area leading to greater sorption.

The study indicates that the three biosorbents are suitable for the removal of fluoride ions. The percentage of fluoride removal increases with adsorbent dose and time at a given initial solute concentration. The fluoride removal efficiency decreases with increasing initial fluoride ion concentration.

\subsection{Stage 3}

From the adsorption study, it is clear that Vetiver root has the potential to be an efficient defluoridating agent ( $80 \%$ removal), so further study was carried out using activated Vetiver root. Powdered activated Vetiver showed higher efficiency (90\%) than the other. The batch sorptive defluoridation of powdered activated vetiver was conducted under variable experimental conditions such as $\mathrm{pH}$, agitation time, dose of adsorbent and particle size.

\subsubsection{Effect of pH}

The adsorption was found to be sufficiently influenced by the $\mathrm{pH}$ of the medium. The effect of $\mathrm{pH}$ change on the defluoridation was carried out within a range of $\mathrm{pH} 2$ 10. Maximum removal was observed around neutral $\mathrm{pH}$ (around neutral $\mathrm{pH}$, the surface will be positively chargedcolumbic interaction between fluoride ion and adsorbent surface was higher) is shown in Figure 5.

In the acidic $\mathrm{pH}$ range, the amount of fluoride adsorbed slightly decreased and this can be attributed to the formation of weak hydrofluoric acid. In alkaline $\mathrm{pH}$ range, there was sharp drop in adsorption which may be due to the competition of the hydroxyl ions with the fluoride for adsorption [16].

\subsubsection{Effect of Agitation Time on Defluoridation}

The effect of agitation time was found to be increasing up to a certain period of time after which the rate of sorption was found to be constant as shown in Figure 6.

\subsubsection{Effect of Sorbent Dosage on Defluoridation}

The response of adsorbent dose on the removal of fluoride is presented in Figure 7. The fluoride uptake increases with the corresponding increase in the amount of adsorbent. Initially, the removal of fluoride increases with the dose but beyond certain dose range, there is no significant increase in removal.

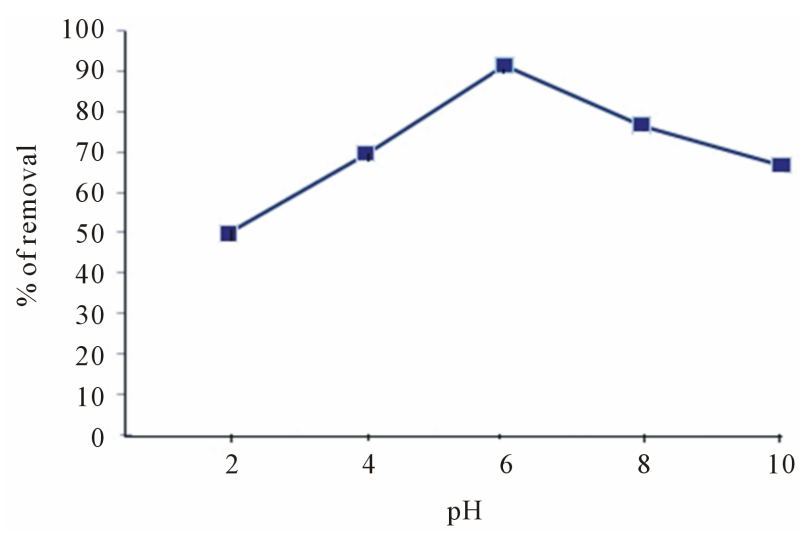

Figure 5. Effect of $\mathrm{pH}$ on sorption of fluoride.

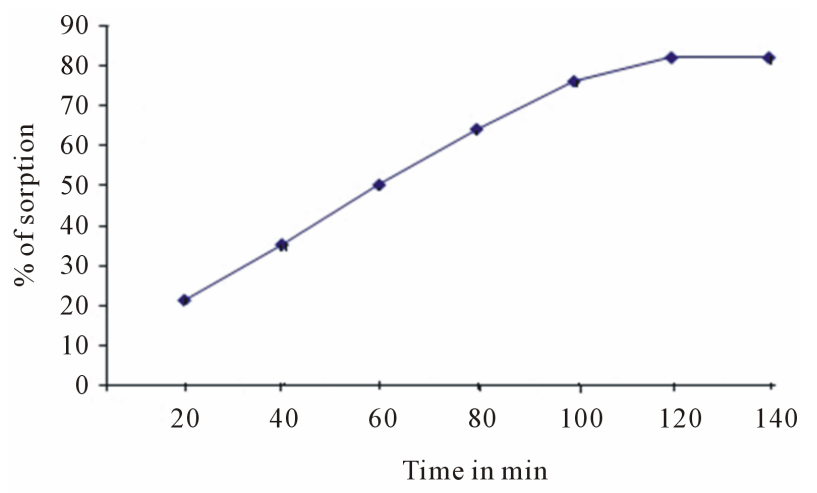

Figure 6. Effect of agitation time on defluoridation.

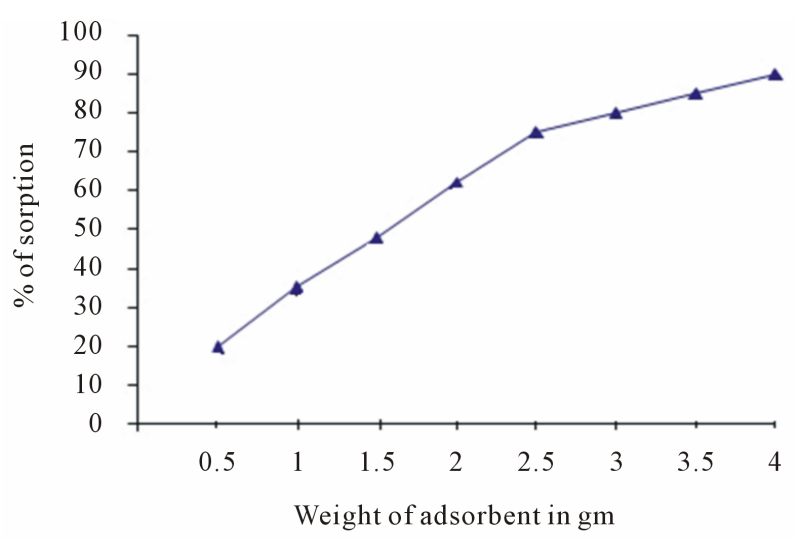

Figure 7. Effect of sorbent dosage on defluoridation. 


\subsubsection{Effect of Particle Size on Sorption of Fluoride}

The effect of particle size on fluoride sorption is given in Figure 8. Increase in particle size from 100 to 500 micron reduces the sorption level. The smaller particles provide more sorption sites and surface area leading to greater sorption.

\subsubsection{Effect of Temperature on Defluoridation}

There is no significant effect of sorption of fluoride observed with varying temperature.

The study indicates that the powdered activated Vetiver root is suitable for the removal of fluoride ions. The percentage of fluoride removal increases with adsorbent dose and time at a given initial solute concentration. The fluoride removal efficiency decreases with increasing initial fluoride ion concentration.

\subsection{Adsorption Isotherm}

The sorption isotherm studies are conducted by varying the initial concentration of fluoride from 1 to $5 \mathrm{mg} / \mathrm{L}$ and maintaining the adsorbent dosage of $0.5 \mathrm{~g}$. Adsorption isotherm of activated Vetiver root mare discussed in Table 1.

\subsubsection{Freundlich Adsorption Isotherm for the Adsorption of Fluoride}

From Figure 9, the observation from the kinetic study are given below

- The value of $k$ and $1 / \mathrm{n}$ are $3.467 \mathrm{mg} / \mathrm{g}$ and $0.357 \mathrm{re-}$ spectively.

- Since the value of the constant $1 / \mathrm{n}$ (adsorption intensity) is less than unity, it indicates favorable adsorption.

- The higher value of $\mathrm{k}$ indicates rate of adsorbate removal is high.

\subsubsection{Langmuir Adsorption Isotherm for the Adsorption of Fluoride}

The observation from Figure $\mathbf{1 0}$ are given below

- The values of Langmuir parameters, $\mathrm{V}_{\mathrm{m}}$ and a are 4.2918 and 0.231 respectively.
- The linear plot obtained indicates the applicability of Langmuir adsorption isotherm for the adsorption of fluoride.

The surface modification of the fluoride adsorbed material was further confirmed through Scanning Electron Microscope image.

SEM micrograph of activated Vetiver adsorbent before fluoride loading was somewhat smooth (as shown in Figure 11), after fluoride adsorption the surface became much rockier in appearance (as shown in Figure 12).

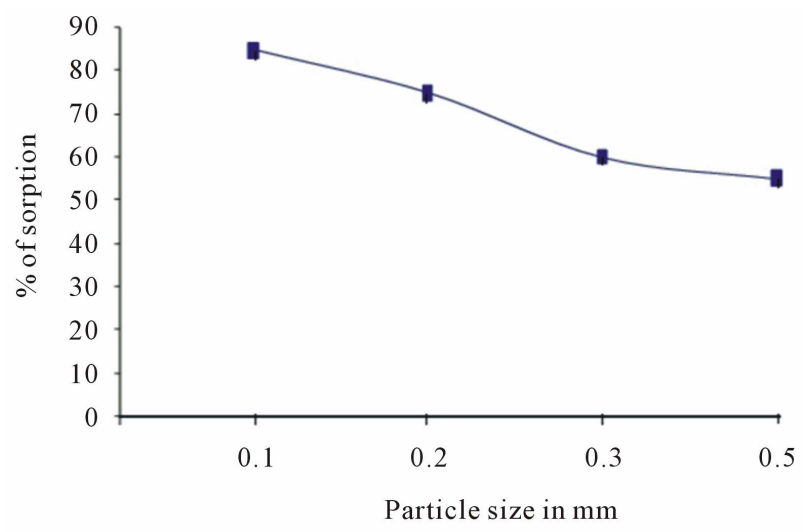

Figure 8. Effect of particle size on sorption of fluoride.

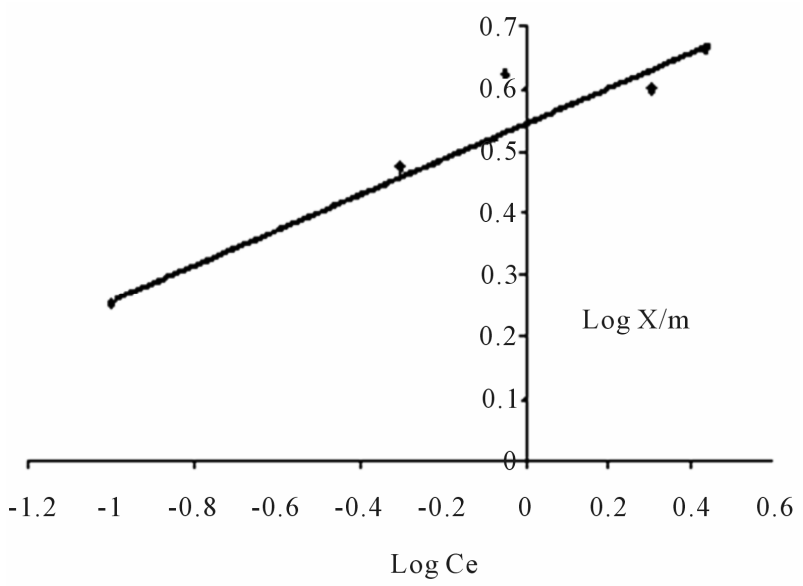

Figure 9. Freundlich adsorption isotherm.

Table 1. Adsorption isotherm of activated vetiver.

\begin{tabular}{cccccccc}
\hline $\mathrm{Ci}(\mathrm{mg} / \mathrm{l})$ & $\mathrm{Ce}(\mathrm{mg} / \mathrm{l})$ & $\mathrm{X}(\mathrm{mg})$ & $\mathrm{m}(\mathrm{g})$ & $\mathrm{X} / \mathrm{m}(\mathrm{mg} / \mathrm{g})$ & $\mathrm{Ce} /(\mathrm{X} / \mathrm{m})$ & $\log \mathrm{Ce}$ & $\log \mathrm{X} / \mathrm{m}$ \\
\hline 1 & 0.1 & 0.9 & 0.5 & 1.8 & 0.056 & -1.000 & 0.255 \\
2 & 0.5 & 1.5 & 0.5 & 3 & 0.167 & -0.301 & 0.477 \\
3 & 0.9 & 2.1 & 0.5 & 4.2 & 0.214 & -0.046 & 0.623 \\
4 & 2 & 2 & 0.5 & 4 & 0.500 & 0.301 & 0.602 \\
5 & 2.7 & 2.3 & 0.5 & 4.6 & 0.587 & 0.431 & 0.663 \\
\hline
\end{tabular}




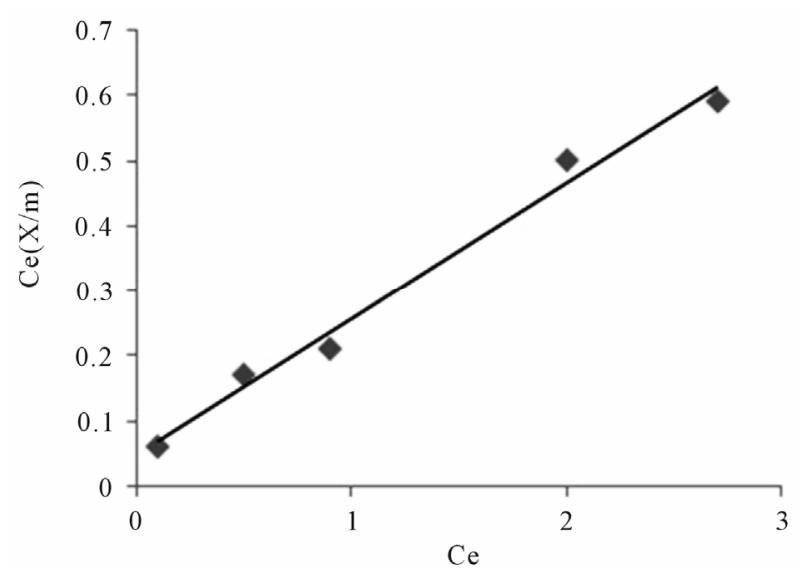

Figure 10. Langmuir adsorption isotherm.

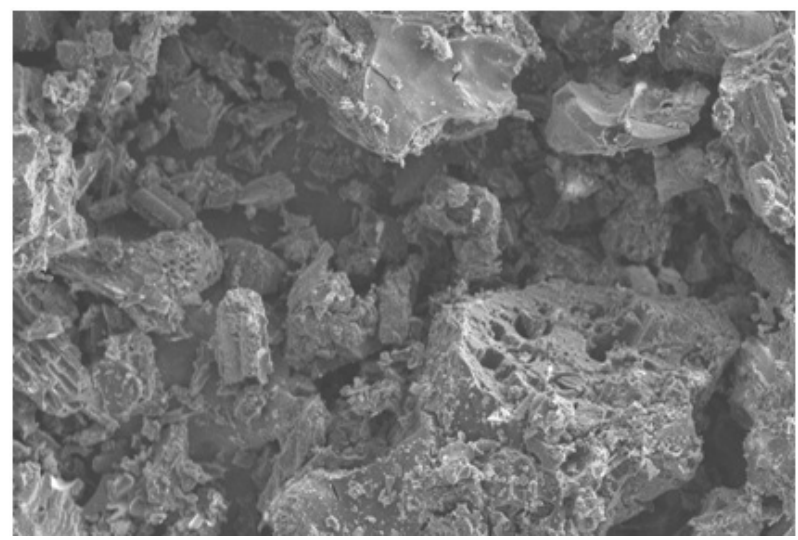

Figure 11. SEM images of free activated vetiver root $(\times 500$ magnification).

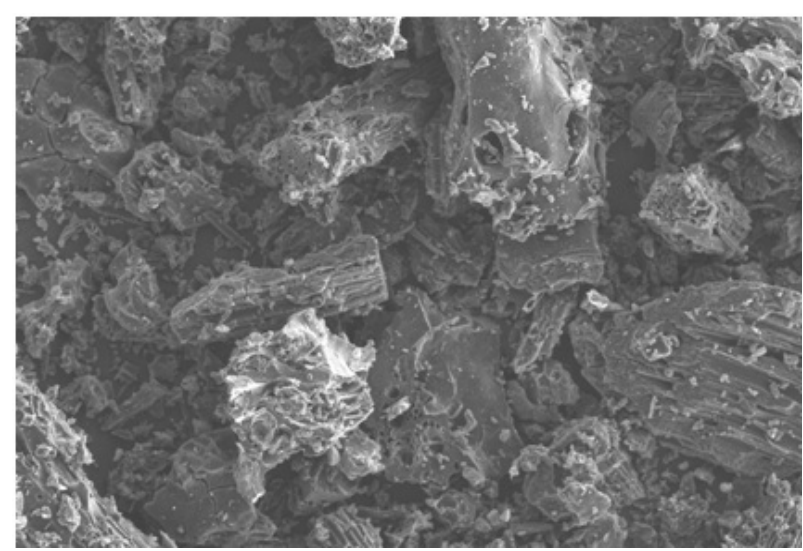

Figure 12. SEM images of fluoride loaded activated vetiver root $(\times 500$ magnification $)$.

\subsection{Fabrication of Domestic Filter Using Tested Material}

Based on the adsorption study of activated Vetiveria zizanioides, a water treatment unit for defluoridation was developed.

The column of an ordinary household water filter (7.5 $\mathrm{cm}$ height and $8 \mathrm{~cm}$ diameter) was packed with four materials in five layers-sand, activated Vetiver root, activated carbon and pebbles are in a ratio of 1:2:4:6. Different weights of Vetiver adsorbent were used for fluoride filtration. The resultant filtrate was measured for fluoride by spectrophotometer using SPADNS method. The efficiency of the column was evaluated through the elution of a solution of known concentration of fluoride. The fluoride removal efficiency of the filter system was found low when the filtrate was collected immediately, that is the time of contact between the sample and Vetiver was small. As the time of contact increased, the efficiency of removal of fluoride also increased and maximum efficiency of fluoride removal was $90 \%$ when the time of contact was increased to 20 minutes. Removal efficiency depends on the amount of activated Vetiver root powder, time of contact and volume of the sample taken. This filter system has a removal efficiency of $90 \%$ fluoride solution with adsorbent regeneration capacity.

\section{CONCLUSION}

Different plant species were studied for testing the efficiency of fluoride removal. Vetiver root was found to be promising for the removal of fluoride. In its activated powdered form, Vetiver root has the potential to be an efficient defluoridating agent. The sorption process of fluoride ion on activated Vetiver root was influenced by many experimenttal conditions. The equilibrium data obtained fitted well with Langmuir and Freundlich isotherms. SEM micrographs of activated Vetiver adsorbent after fluoride loading confirmed the adsorption of fluoride.

\section{ACKNOWLEDGEMENTS}

The authors are thankful to the Department of Science and Technology for the financial support.

\section{REFERENCES}

[1] Kharb, P. and Susheela, A.K. (1994) Fluoride ingestion in excess and its effect on organic and certain inorganic constituents of soft tissues. Medical Science Research, 22, 43-44.

[2] Varier, P.S. (1996) Indian medicinal plants: A compendium of 500 species, Vol. 1-5. Orient Longman Ltd., Madras

[3] Antu, C.D. and Harikumar, P.S. (2007) Genesis of fluoride in the shallow unconfined aquifer of muthalmada area in Bharatapuzha Basin. Proceedings of XIX Kerala Science Congress, 29-31 January 2007, Kannur.

[4] Hichour, M., Persin, F., Sandeaux, J. and Gavach, C. (2000) Fluoride removal from waters by Donnan dialysis. Separation and Purification Technology, 18, 1-11. 


\section{doi:10.1016/S1383-5866(99)00042-8}

[5] Folkard, G.K., Grant, W.D. and Sutherland, J.P. (1990) Natural coagulants for small scale water treatment: Potential applications. Experiences in the Development of Small-Scale Water Resources in Rural Areas: Proceedings of the International Symposium on Development of SmallScale Water Resources in Rural Areas. Carl Duisberg Gesellschaft, South East Asia Program Office, Bangkok, 115-123.

[6] Amor, Z., Malki, S., Taky, M., Bariou, B., Mameri, N. and Elmidaoui, A. (1998) Optimization of fluoride removal from brackish water by electrodialysis. Desalination, 120, 263-271. doi:10.1016/S0011-9164(98)00223-9

[7] Hichour, M., Persin, F., Molenat, J., Sandeaux, J. and Gavach, C. (1999), Fluoride removal from diluted solutions by Donnan dialysis with anion-exchange membranes. Desalination, 122, 53-62. doi:10.1016/S0011-9164(99)00027-2

[8] Rubel, J.F. (1983) The removal of excess fluoride from drinking water by the activated alumina method. In: Shupe, J.L., Peterson, H.P. and Leone, N.C. Eds., Fluoride effects on vegetation animals and humans. Paragon Press, Salt Lake City, 345-349

[9] Yang, M., Hashimoto, T., Hoshi, N. and Myoga, H. (1999) Fluoride removal in a fixed bed packed with granular calcite. Water Research, 33, 3395-3402. doi:10.1016/S0043-1354(99)00052-4

[10] Li, Y.H., Wang, S., Cao, A., Zhao, D., Zhang, X., Xu, C.,
Luan, Z., Ruan, D., Liang, J., Wu, D. \& Wei, B. (2001) Adsorption of fluoride from water by amorphous alumina supported on carbon nanotubes. Chemical Physics Letters, 350, 412-416. doi:10.1016/S0009-2614(01)01351-3

[11] Wang, Y. and Reardon, E.J. (2001) Activation and regeneration of a soil sorbent for defluoridation of drinking water. Applied Geochemistry, 16, 531-539. doi:10.1016/S0883-2927(00)00050-0

[12] Christopher, J., Kenneth, G., Ishida, P. and Richard, M. (2004) Bold testing of drinking water treatment: Copolymers for compatibility with polyamide reverse osmosis membranes. 9th World Filtration Congress, 18-22 April 2004, New Orleans, 1-10.

[13] Srimurali, M., Pragathi, A. and Karthikeyan, J. (1998) A study on removal of fluorides from drinking water by adsorption onto low-cost materials. Environmental Pollution, 99, 285-289. doi:10.1016/S0269-7491(97)00129-2

[14] APHA. (2005) Standard method for the examination of water and waste water. 21st Edition, American Public Health Association, Washington DC, 85-86.

[15] Murugan, M. and Subramanian, E. (2006) Studies on defluoridation of water by Tamarind seed, an unconventional biosorbent. Journal of Water and Health, 4, 453461.

[16] Kumar, S., Gupta, A. and Yadav, J.P. (2008) Removal of fluoride by thermally activated carbon prepared from neem (Azadirachta indica) and kikar (Acacia arabica) leaves. Journal of Environmental Biology, 29, 227-232. 